African Journal of Pharmacy and Pharmacology Vol. 6(42), pp. 2945-2949, 15 November, 2012

Available online at http://www.academicjournals.org/AJPP

DOI: 10.5897/AJPP12.958

ISSN 1684-5315 @2012 Academic Journals

Full Length Research Paper

\title{
Relationship among C-reactive protein, iron status, oxidative stress, and pulmonary tuberculosis
}

Bing Sun, Yaqin Yang, Fang Ren, Qingjiang Wang, Junwei Cui, Jinhe Shi and Xiuqin Cui

Department of Tuberculosis, the First Affiliated Hospital of Xinxiang Medical University, Weihui 453100, China

Accepted 1 October, 2012

This study aims to assess the effects of acute tuberculosis and drug treatment on oxidative stress markers [malondialdehyde (MDA) and total antioxidant status (TAS)], C-reactive protein (CRP), and body iron index. A total of 20 patients with active tuberculosis (treatment group) and $\mathbf{5 0}$ healthy subjects (control group) were selected. MDA, TAS, serum CRP, serum iron, serum total iron binding capacity, transferrin saturation, and serum ferritin in the treatment (before and after) and control groups were evaluated. After two months of treatment, MDA, CRP, and ferritin significantly decreased, whereas TAS, serum iron, and transferrin saturation significantly increased. Serum total iron binding force demonstrated a significant effect. In the first two months of treatment, oxidative stress was significantly improved, and the inflammation was under control. CRP levels increased inflammatory response in tuberculosis. Drug therapy significantly improved the iron status of patients with anemia of chronic inflammation.

Key words: Tuberculosis, oxidant/antioxidant status, C-reactive protein, iron status.

\section{INTRODUCTION}

In recent years, the incidence rate of pulmonary tuberculosis and other forms of tuberculosis has increased, resulting in serious effects on human physical and mental health. C-reactive protein (CRP) is an acutephase protein synthesized by proinflammatory cytokinereactive hepatocytes. CRP is related to the clinical responses of patients. The concentration of CRP in normal human blood is usually less than $8 \mathrm{mg} / \mathrm{L}$. However, this value increases in the presence of inflammation, tissue damage, local ischemia, cancer, and other diseases (Liu et al., 2010; Hamidon et al., 2004; Bhutto et al., 2011). During an infection, inflammatory cells infiltrate and release endogenous neurotransmitters to stimulate hepatocytes. This process accelerates the synthesis of CRP. Therefore, serum CRP rapidly rises. Individuals infected with tubercle bacilli have low body resistance and immunity,

\footnotetext{
${ }^{*}$ Corresponding author. E-mail: xiuqincui@126.com.
}

allowing the bacteria to proliferate rapidly. This type of infection causes pulmonary-specific reactions (such as tuberculosis nodule formation) and non-specific reactions (general inflammatory reaction) as the tubercle bacilli increase in quantity and enhance their virulence. Tissue injury extent and tissue repair time after treatment exhibit some differences among patients with active tuberculosis. Serum CRP increase has different extents of changes (Toriola et al., 2011; French et al., 2011; Herlina et al., 2011; Wilson et al., 2011; Guo et al., 2010). CRP concentration in blood gradually decreases to the normal level as the disease regresses and as tissue structure and function recover. These characteristics of CRP can be used for the diagnosis, treatment, and prognosis of various diseases.

Studies confirm that reactive oxygen species (ROS) reaction, oxidative stress, and lipid peroxidation stress demonstrate a pathological increase in patients with pulmonary tuberculosis and other forms of tuberculosis (Plit et al., 1998; van Doorn et al., 2003). Mycobacteria activate 
mononuclear and polymorphonuclear phagocytes with antibacterial activity to generate ROS, which possibly damages hosts (Herlina et al., 2011). Iron plays a crucial role in tuberculosis infection. On one hand, iron influences innate and acquired immunological reactions. On the other hand, it is necessary for bacterial replication (Isanaka et al., 2012; Lee et al., 2012; Johnson and Wessling-Resnick, 2012).

This study aims to assess the effects of the first two months of treatment on the content of serum lipid peroxidation products via evaluating malondialdehyde (MDA), total antioxidant status (TAS), CRP, and body iron index [serum iron, total iron binding capacity (TIBC), transferrin saturation, and serum ferritin] in the treatment and healthy control groups.

\section{MATERIALS AND METHODS}

\section{Subjects}

Patients treated in the respiratory-system outpatient department from December 2007 to September 2010 were selected. Laboratory examination was conducted at the same time. The inclusion criteria were typical pulmonary tuberculosis symptoms: (1) chest radiographs showing fibrous cavitary pulmonary infiltrates and (2) sputum specimen at least positive for acid-fast bacillus through Ziehl-Neelsen staining. The exclusion criteria were as follows: (1) smokers, (2) history of drug use (including vitamins, iron, and antibiotics), (3) blood transfusion history and no recent bleeding, (4) not pregnant and lactating, (5) not menstruating during blood acquisition, (6) previously receiving pulmonary tuberculosis treatment, and (7) patients with lung pathology. Only 20 cases of active pulmonary tuberculosis were found for the treatment group after the patients were audited and examined (14 males and 6 females, with ages ranging from 23 to 70 years old). The average age of the patients was $39.35 \pm 14.34$ years old. Follow-up was conducted after the preliminary two-month treatment. In addition, 50 healthy volunteers without tuberculosis history were selected for the control group (36 males and 14 females). The ages of the control group members ranged from 18 to 70 years old. The average age was $38.45 \pm 14.67$ years old. This study was conducted in accordance with the declaration of Helsinki. This study was conducted with approval from the Ethics Committee of the First Affiliated Hospital of Xinxiang Medical College. Written informed consent was obtained from all participants.

\section{Treatment methods}

In the first two months of treatment, four tablets of Rimstar $\AA$ and a fixed-dose tablet containing four kinds of anti-tuberculosis drugs were orally administered to patients daily before breakfast. The fixed-dose tablet contained $75 \mathrm{mg}$ Isoniazid (INH), $150 \mathrm{mg}$ Rifampin, $400 \mathrm{mg}$ Pyrazinamide, and $275 \mathrm{mg}$ Ethambutol). Approximately, $10 \mathrm{ml}$ of blood was drawn from the vein of each patient before the treatment. Another $10 \mathrm{ml}$ sample of blood was drawn from the vein of each patient at the end of the intensive twomonth treatment. After each acquisition, blood was centrifuged to separate the serum. The serum was frozen and stored at $-20^{\circ} \mathrm{C}$ for later use. Blood samples from the control group were also collected and processed through the same method.

\section{Detection methods}

Bathyran test (thiobarbituric acid, TBA) was conducted to detect MDA content. A Randox Total Antioxidant Status (TAS) kit (Landau Pharmaceutical Company Limited, Antrim, England) was used to detect TAS content, and a CRP latex kit (Chemelex, Spain) was used to semi-quantitatively detect CRP through the slide agglutination method. Through the colorimetric method, a Ferene detection kit (Biolabo reagent, France) was used to directly detect the content of serum iron. An REF 92308 detection kit (Biolabo reagent, France) was used to detect TIBC content. Transferrin saturation was calculated as follows: transferrin saturation $(\%)=$ serum ferrum concentration $\times 100 /$ TIBC

Lastly, VIDAS instrument and a Ferritin reagent kit (BioMerieux Company, France) were used to detect serum ferritin through the enzyme-linked fluorescence immunoassay method.

\section{Statistical analysis}

The Statistical Package for Social Sciences (SPSS) 13.0 software was used for statistical analysis. Data were expressed as mean \pm standard deviation ( $\bar{x} \pm S D$ ). The $t$-test was used for statistical comparison. The Fisher-Freeman-Halton test was used to compare the CRP detection results between the treatment and control groups. The Wilcoxon signed-rank test was used to compare the CRP detection results of the patients with pulmonary tuberculosis before and after treatment. Linear regression analysis and Pearson correlation coefficient $(r)$ were used to determine the relationship among the different parameters. Analysis of variance was used to determine the relationship of CRP with other parameters. $\mathrm{P}<0.05$ was considered to indicate statistically significant differences.

\section{RESULTS}

\section{Indicator detection}

Tables 1 and 2 show the MDA, TAS, serum iron content, TIBC, transferrin saturation, ferritin, and CRP in the control and treatment groups before and after treatment for two months. Before the treatment, the serum CRP content in the treatment group significantly increased $(P<$ 0.01) compared with that in the control group. After two months of treatment, the CRP content significantly reduced $(P<0.01)$. Before the treatment, both serum iron and transferrin saturation in the treatment group significantly decreased compared with those in the control group $(P<0.01)$. Meanwhile, serum ferritin content significantly increased $(P<0.01)$. However, an obvious difference in TIBC content was found between the treatment and control groups. After two months of treatment, both serum iron content $(P<0.01)$ and transferrin saturation $(P<0.01)$ in the treatment group significantly increased. Serum ferritin content significantly decreased $(P<0.01)$, whereas TIBC had no obvious change. Before the treatment, serum MDA content was significantly higher $(P<0.01)$ and serum TAS was significantly lower $(P<0.01)$ in the treatment group than in the control group. Serum MDA and TAS contents after two months of treatment significantly reduced and increased (both 
Table 1. Comparison of C-reactive protein before and after treatment between tuberculosis patients and healthy control.

\begin{tabular}{|c|c|c|c|c|c|c|}
\hline \multirow{3}{*}{ CRP (mg/L) } & \multirow{2}{*}{\multicolumn{2}{|c|}{ Control $(n=50)$}} & \multicolumn{4}{|c|}{ Tuberculosis patients } \\
\hline & & & \multicolumn{2}{|c|}{ Before treatment $(n=20)$} & \multicolumn{2}{|c|}{ After treatment $(n=20)$} \\
\hline & Number & $\%$ & Number & $\%$ & Number & $\%$ \\
\hline$<6$ & 39 & 78.0 & 0 & 0.0 & 6 & 30.0 \\
\hline 6 & 9 & 18.0 & 3 & 15.0 & 10 & 50.0 \\
\hline 12 & 2 & 4.0 & 6 & 30.0 & 3 & 15.0 \\
\hline 24 & 0 & 0.0 & 5 & 25.0 & 1 & 5.0 \\
\hline 48 & 0 & 0.0 & 2 & 10.0 & 0 & 0.0 \\
\hline 96 & 0 & 0.0 & 4 & 20.0 & 0 & 0.0 \\
\hline$P$ value & \multicolumn{2}{|c|}{ - } & \multicolumn{2}{|c|}{$<0.01$} & \multicolumn{2}{|c|}{$<0.01$} \\
\hline
\end{tabular}

Table 2. Comparison of malondialdehyde, iron status, oxidative stress before and after treatment between tuberculosis patients and healthy control $(\bar{x} \pm \mathrm{SD})$.

\begin{tabular}{|c|c|c|c|}
\hline \multirow{2}{*}{ Item } & \multirow{2}{*}{ Control $(n=50)$} & \multicolumn{2}{|c|}{ Tuberculosis patients $(n=20)$} \\
\hline & & Before treatment & After treatment \\
\hline $\operatorname{MDAb}(\mu \mathrm{mol} / \mathrm{L})$ & $1.31 \pm 0.15$ & $3.19 \pm 0.53^{* \star *}$ & $2.83 \pm 0.57^{\star * \star \$ \S \S}$ \\
\hline TAS (mmol/L) & $1.79 \pm 0.29$ & $1.05 \pm 0.11^{* \star *}$ & $1.28 \pm 0.12^{\star * \star \S \S \S}$ \\
\hline Iron $(\mu \mathrm{g} / \mathrm{dl})$ & $99.05 \pm 28.35$ & $55.73 \pm 16.89^{* * *}$ & $77.98 \pm 29.31^{* * \star \S \S \S}$ \\
\hline $\operatorname{TIBC}(\mu \mathrm{g} / \mathrm{dl})$ & $398.21 \pm 69.52$ & $395.48 \pm 149.47$ & $377.65 \pm 137.30$ \\
\hline Transferrin saturation (\%) & $26.45 \pm 8.34$ & $16.90 \pm 7.20^{\star \star *}$ & $22.38 \pm 8.56^{\S \S \S}$ \\
\hline Ferritin $(\mathrm{ng} / \mathrm{ml})$ & $184.31 \pm 66.26$ & $442.75 \pm 318.34^{\star \star *}$ & $186.75 \pm 128.61^{\$ \$ s}$ \\
\hline
\end{tabular}

${ }^{* * *} \mathrm{P}<0.01$ vs. the control group; TAS = total antioxidant status; ${ }^{\S \S \S} \mathrm{P}<0.01$ vs. before treatment; TIBC $=$ Total Iron Binding Capacity; ${ }^{*} \mathrm{P}<0.05$ vs. the control group.

Table 3. The relationship between C-reactive protein and MDA.

\begin{tabular}{cccc}
\hline CRP & $\mathbf{n}$ & MDA $(\overline{\boldsymbol{x}} \mathbf{\pm S D})$ & P value \\
\hline$<6$ & 45 & $1.67 \pm 0.69$ & \\
6 & 22 & $2.62 \pm 0.79$ & \\
12 & 11 & $2.71 \pm 0.89$ & $<0.01$ \\
24 & 6 & $3.28 \pm 0.48$ & \\
48 & 2 & $3.00 \pm 0.14$ & \\
96 & 4 & $3.36 \pm 0.68$ & \\
\hline
\end{tabular}

$P<0.01)$, respectively, compared with those before the treatment.

\section{Correlation analysis}

An extremely significant negative correlation between serum MDA and TAS $(r=-0.852, P<0.01)$ was found in the treatment (before and after) and control groups. Further, an extremely significant positive correlation was found between serum ferritin and MDA $(r=0.348$,
$P<0.01)$. An extremely significant negative correlation between serum ferritin and TAS $(r=-0.345, P<0.01)$ was also recorded (Tables 3 to 5).

\section{DISCUSSION}

Studies suggest that CRP concentration in all preliminarily diagnosed patients is higher than that in the control group. Serum CRP level was significantly reduced in the first two months of treatment. The CRP level in the treatment group obviously increased and then returned to normal level after several weeks of treatment. Therefore, serum CRP level is related to clinical reaction. CRP concentration is higher in patients with a more severe case of pulmonary tuberculosis and a worse prognosis (Gordeuk et al., 2009). The reason is that the patients possibly has pulmonary cavity, suggesting that pulmonary dysfunction is more severe. Moreover, studies revealed that the CRP content in patients with pulmonary cavity is higher than that in patients without pulmonary cavity (Seyedrezazadeh et al., 2008).

In this study, before the treatment, both serum iron content and transferrin saturation in the treatment group 
Table 4. The relationship between C-reactive protein and TAS.

\begin{tabular}{cccc}
\hline CRP & $\mathbf{n}$ & MDA $(\bar{x} \pm$ SD $)$ & P value \\
\hline$<6$ & 45 & $1.86 \pm 0.48$ & \\
6 & 22 & $1.43 \pm 0.38$ & \\
12 & 11 & $1.26 \pm 0.29$ & $<0.01$ \\
24 & 6 & $1.10 \pm 0.10$ & \\
48 & 2 & $1.00 \pm 0.09$ & \\
96 & 4 & 1.010 .12 & \\
\hline
\end{tabular}

Table 5. The relationship between C-reactive protein and ferritin.

\begin{tabular}{cccc}
\hline CRP & $\mathbf{n}$ & Ferritin $(\bar{x} \pm$ SD $)$ & P value \\
\hline$<6$ & 45 & $143.29 \pm 88.10$ & \\
6 & 22 & $95.48 \pm 96.54$ & \\
12 & 11 & $204.35 \pm 188.57$ & $<0.01$ \\
24 & 6 & $420.10 \pm 424.83$ & \\
48 & 2 & $562.17 \pm 322.05$ & \\
96 & 4 & $654.49 \pm 280.00$ & \\
\hline
\end{tabular}

were significantly reduced when compared with those in the control group. These two parameters significantly increased after treatment. The conversion of iron from the available status of transferrin binding into the storage status of ferritin binding possibly induces hypoferremia in tuberculosis patients. Cytokine can mediate and defend against pathogenic microorganisms. This situation is possibly improved, because cytokine can effectively prevent microorganisms from absorbing iron (Heroux et al., 2011). Some experts believe that mycobacteria acquire iron from the iron-binding proteins of the host's own transferrin/ferritin. These bacteria capture iron carriers to obtain iron from the host by releasing a type of iron called exochelin (Farhana et al., 2010; Wilson et al., 2011). Exochelin transfers iron onto mycobacterium auxin (in mycobacterium cell wall). Some experts still believe that patients with pulmonary tuberculosis usually suffer from anemia because of the restriction to available iron (Friis et al., 2009). Available iron restriction in patients with pulmonary tuberculosis is an important component of the host's natural immunity. This component induces acute-phase reactions (reduce serum iron content mainly by iron chelation). Serum proteins (such as transferrin, ferritin, and lactoferrin) bind the iron chelated by the host, thus restricting the host's own iron-induced cell injury. The host's purpose is to induce pathogenic iron deficiency. In addition, lower TIBC concentration in patients with pulmonary tuberculosis is an acute-phase reaction (Ko et al., 2011). Given that transferrin is a kind of acutephase protein, its presence in serum possibly reduces inflammatory condition. This study suggests that although iron supplement was given to the patients, serum iron content, transferrin saturation, and ferritin all improved after two months of treatment. Host cells (namely macrophages, neutrophilic granulocytes, and monocytes) generate a great number of ROS to kill mycobacteria. Lipid peroxidation is one manifestation of ROS. These active substances often have cytotoxicity and possibly cause tissue injury (such as pulmonary fibrosis and pulmonary dysfunction in patients with pulmonary tuberculosis) if the host's antioxidant defense system has a defect. Patients with pulmonary tuberculosis suffer more easily from malnutrition, because of their lower antioxidant ability when compared with healthy individuals (Hu and Coates, 2011). In addition, tuberculosis patients cannot generate enough antioxidants to combat increasing oxidative stress (Oberley-Deegan et al., 2010).

This study only detects TAS of patients rather than antioxidant enzymes and antioxidant molecules. The TAS level in patients with pulmonary tuberculosis was lower, which may be due to malnutrition or adynamia for counteracting the heavy load of free radicals. This study shows an extremely significant negative correlation between serum MDA and TAS in the treatment (before and after) and control groups. This result suggests that an increase in the utilization rate of ROS in patients with pulmonary tuberculosis is an important factor in decreasing antioxidant substance concentration. A patient simultaneously suffering from malnutrition (leads to a decrease in antioxidant substance "supplement") and ROS generation enhancement (leads to an increase in the utilization rate of ROS) possibly exhibits a pathogenic cycle that significantly enhances oxidative stress during tuberculosis infection.

Compared with the healthy control group, the serum MDA content and antioxidant status in the patients preliminarily diagnosed with pulmonary tuberculosis were significantly higher and lower, respectively. In addition, two months of anti-tuberculosis drug treatment could significantly reduce MDA content and significantly increase TAS in patients with pulmonary tuberculosis. Although, these parameters were significantly improved after the treatment, significant differences were still found compared with the control values. Lipid peroxidation products and TAS increased and decreased, respectively, in the patients preliminarily diagnosed with active pulmonary tuberculosis. This result suggests that oxidative stress reactions occur in these patients. In addition, two months of treatment reduced MDA content and increased TAS, indicating good efficiency of the drugs. Oxidative stress reactions still occur in patients even after two months of chemotherapy.

This study suggests that pulmonary tuberculosis is related to oxidative stress and that it can increase MDA and reduces TAS. In the first two months of antituberculosis treatment (intensive treatment phase), the 
drugs can reduce serum MDA content, increase TAS, and decrease oxidative stress. The increase in acute-phase protein (CRP and serum ferritin) content suggests that pulmonary tuberculosis is an inflammation-related reaction. Administration of treatment in the first two months inhibits inflammation. Therefore, these proteins are significantly reduced. Although, the possibility of iron deficiency anemia cannot be excluded, imbalance in body iron index suggests that patients preliminarily diagnosed with pulmonary tuberculosis usually exhibit chronic inflammatory anemia and that anti-tuberculosis therapy can obviously improve anemia.

\section{REFERENCES}

Bhutto IA, Baba T, Merges C, Juriasinghani V, McLeod DS, Lutty GA (2011). C-reactive protein and complement factor $\mathrm{H}$ in aged human eyes and eyes with age-related macular degeneration. Br. J. Ophthalmol. 95:1323-1330.

Farhana A, Guidry L, Srivastava A, Singh A, Hondalus MK, Steyn AJ (2010). Reductive stress in microbes: implications for understanding Mycobacterium tuberculosis disease and persistence. Adv. Microb. Physiol. 57:43-117.

French MA, Oliver BG, Elliott JH, Price P (2011). Plasma biomarkers in the prediction and diagnosis of tuberculosis-associated immune reconstitution inflammatory syndrome. AIDS 25:1676-1677.

Friis H, Range N, Braendgaard Kristensen C, Kaestel P, Changalucha J, Malenganisho W, Krarup $H$, Magnussen $P$, Bengaard Andersen A (2009). Acute- phase response and iron status markers among pulmonary tuberculosis patients: a cross-sectional study in Mwanza, Tanzania. Br. J. Nutr. 102:310-317.

Gordeuk VR, Moyo VM, Nouraie M, Gangaidzo IT, Murphree NL, Gomo ZA, Boelaert JR, Weiss G (2009). Circulating cytokines in pulmonary tuberculosis according to HIV status and dietary iron content. Int. J. Tuberc. Lung Dis. 13:1267-1273.

Guo LX, Ma YZ, Li HW, Xue HB, Peng W, Luo XB (2010). Variety of ESR and C-reactive protein levels during perioperative period in spinal tuberculosis]. Zhongguo Gu Shang 23:200-202.

Hamidon BB, Sapiah S, Nawawi H, Raymond AA (2004). The prognostic value of C-reactive protein (CRP) levels in patients with acute ischaemic stroke. Med. J. Malaysia 59:631-637.

Herlina M, Nataprawira HM, Garna H (2011). Association of serum Creactive protein and leptin levels with wasting in childhood tuberculosis. Singapore Med. J. 52:446-450.
Heroux MS, Mohan AD, Olsen KW (2011). Ligand migration in the truncated hemoglobin of Mycobacterium tuberculosis. IUBMB Life 63:214-220.

$\mathrm{Hu}$ Y, Coates AR (2011). Mycobacterium tuberculosis acg gene is required for growth and virulence in vivo. PLoS One 6:e20958.

Isanaka S, Aboud S, Mugusi F, Bosch RJ, Willett WC, Spiegelman D, Duggan C, Fawzi WW (2012). Iron Status Predicts Treatment Failure and Mortality in Tuberculosis Patients: A Prospective Cohort Study from Dar es Salaam, Tanzania. PLoS One 7:e37350.

Johnson EE, Wessling-Resnick M (2012). Iron metabolism and the innate immune response to infection. Microbes Infect. 14:207-216.

Ko MK, Saraswathy S, Parikh JG, Rao NA (2011). The role of TLR4 activation in photoreceptor mitochondrial oxidative stress. Investig. Ophthalmol. Vis. Sci. 52:5824-5835.

Lee CN, Wang YM, Lai WF, Chen TJ, Yu MC, Fang CL, Yu FL, Tsai YH, Chang WH, Zuo CS, Renshaw PF (2012). Super-paramagnetic iron oxide nanoparticles for use in extrapulmonary tuberculosis diagnosis. Clin. Microbiol. Infect. 18:E149-157.

Liu N, Liu JT, Ji YY, Lu PP (2010). C-reactive protein triggers inflammatory responses partly via TLR4/IRF3/NF-KB signaling pathway in rat vascular smooth muscle cells. Life Sci. 87:367-374

Oberley-Deegan RE, Rebits BW, Weaver MR, Tollefson AK, Bai X, McGibney M, Ovrutsky AR, Chan ED, Crapo JD (2010). An oxidative environment promotes growth of Mycobacterium abscessus. Free Radic. Biol. Med. 49:1666-1673.

Plit ML, Theron AJ, Fickl H, van Rensburg CE, Pendel S, Anderson R (1998). Influence of antimicrobial chemotherapy and smoking status on the plasma concentrations of vitamin $\mathrm{C}$, vitamin $\mathrm{E}$, beta-carotene, acute phase reactants, iron and lipid peroxides in patients with pulmonary tuberculosis. Int. J. Tuberc. Lung Dis. 2:590-596.

Seyedrezazadeh E, Ostadrahimi A, Mahboob S, Assadi Y, Ghaemmagami J, Pourmogaddam M (2008). Effect of vitamin E and selenium supplementation on oxidative stress status in pulmonary tuberculosis patients. Respirology 13:294-298.

Toriola AT, Grankvist K, Agborsangaya CB, Lukanova A, Lehtinen M, Surcel HM (2011). Changes in pre-diagnostic serum C-reactive protein concentrations and ovarian cancer risk: a longitudinal study. Ann. Oncol. 22:1916-1921.

van Doorn HR, Claas EC, Templeton KE, van der Zanden AG, te Koppele Vije A, de Jong MD, Dankert J, Kuijper EJ (2003). Detection of a point mutation associated with high-level isoniazid resistance in Mycobacterium tuberculosis by using real-time PCR technology with 3'-minor groove binder-DNA probes. J. Clin. Microbiol. 41:4630-4635.

Wilson D, Badri M, Maartens G (2011). Performance of serum Creactive protein as a screening test for smear-negative tuberculosis in an ambulatory high HIV prevalence population. PLoS One 6:e15248. 